\title{
Reverse Phase High Performance Liquid Chromatography for the Quantification of Eurycomanone in Eurycoma longifolia Jack (Simaroubaceae) Extracts and their Commercial Products
}

\author{
Nursyazura Khari, Abdalrahim FA Aisha and Zhari Ismail* \\ Department of Pharmaceutical Chemistry, School of Pharmaceutical Sciences, Universiti Sains Malaysia, Minden 11800, Pulau \\ Pinang, Malaysia
}

*For correspondence: Email: zhari@usm.my; Tel: +604-653-2242

\begin{abstract}
Purpose: To develop a reverse phase high performance liquid chromatography (HPLC) method for the determination of eurycomanone in E. longifolia Jack (Simaroubaceae) aqueous root extract and their commercial products.

Methods: Analysis was carried out using reverse phase HPLC at $254 \mathrm{~nm}$ and a gradient mobile phase that comprised of acetonitrile and $0.1 \%$ formic acid. Flow rate was $1 \mathrm{ml} / \mathrm{min}$ and separation was done using Phenomenex, Luna C18 column $(150 \mathrm{~mm} \times 4.6 \mathrm{~mm}, 5 \mu \mathrm{m})$. Validation tests were performed in order to demonstrate the linearity, precision, accuracy, limit of detection (LOD) and limit of quantification (LOQ) of the method.

Results: Linearity was in the range $0.1-50.0 \mu \mathrm{g} / \mathrm{ml}\left(R^{2}=0.9999\right)$. Precision, as relative standard deviation of retention time and peak area of reference compound was $<0.14$, and $<2.75 \%$, respectively. Accuracy, as percent recovery of eurycomanone, was in the range $94.2-99.8 \%$ while $\mathrm{LOD}$ and $\mathrm{LOQ}$ were $0.293 \pm 0.100$ and $0.887 \pm 0.300 \mu \mathrm{g} / \mathrm{ml}$, respectively. Eurycomanone concentration in E. longifolia extracts and commercial products was $0.89-3.28$, and $0.07-0.16 \%$, respectively. Analysis of the ethanol extract and chloroform sub-extract showed high resolution of $>10$ peaks, which indicate the suitability of the method for the analysis of extracts prepared in organic solvents as well. Conclusion: The proposed method shows good linearity, precision, accuracy and high sensitivity. The method can be applied in the routine quantification of eurycomanone for quality control of $E$. longifolia extracts and commercial products.
\end{abstract}

Keywords: Eurycoma longifolia Jack, Tongkat Ali, Eurycomanone, Validation

Tropical Journal of Pharmaceutical Research is indexed by Science Citation Index (SciSearch), Scopus, International Pharmaceutical Abstract, Chemical Abstracts, Embase, Index Copernicus, EBSCO, African Index Medicus, JournalSeek, Journal Citation Reports/Science Edition, Directory of Open Access Journals (DOAJ), African Journal Online, Bioline International, Open-J-Gate and Pharmacy Abstracts

\section{INTRODUCTION}

Eurycoma longifolia Jack or Tongkat Ali (Simaroubaceae) is attracting increased interest due to its multiple pharmacological effects including aphrodisiac, anti-malarial, anti-ulcer, anti-tumour, anti-parasitic, and anti-hypertension effects [1-6]. E. longifolia is available commercially as capsules of raw root powder, capsules of root water extract, mixed with other aphrodisiac herbs, or as additive with tea and coffee [7]. Various bioactive compounds have been identified in $E$. longifolia such as 9hydroxycanthin-6-one, 9-hydroxycanthin-6-one noxide, 9-methoxycanthin-6-one, 9-methoxycanthin-6-one $n$-oxide, $\beta$-carboline-1-propionic acid, $\quad \beta$-7-methoxycarboline-1-propionic acid, eurycomanol, eurycomanol-2-O- $\beta$-D-glucoside, 
13- $\beta$-I,8dihydroeurycomanol, 14,15 -dihydroxyklaineanone and eurycomanone [8-11]. Eurycomanone is the main compound in $E$. longifolia. However, its high toxicity limits its therapeutic application [12]. According to Malaysian standards, eurycomanone concentration in E. longifolia extracts should be in the range $0.8-1.5 \%$ [13]. Therefore, $E$. longifolia products must be standardized to comply with the set standards in order to protect consumers from possible toxic effects. Few methods are available for standardization of $E$. longifolia extracts or commercial products including a RP-HPLC for analysis of eurycomanone in serum for pharmacokinetics [14], and HPLC for determination of 9-methoxycanthin-6-one, 3-methylcanthin-5,6-dione and its 9-methoxy analogue in E. longifolia Jack [15], and HPLC for determination of 9methoxycanthin-6-one in plasma for pharmacokinetics [16], and HPLC method for determination of various compounds in $E$. longifolia extracts [17].

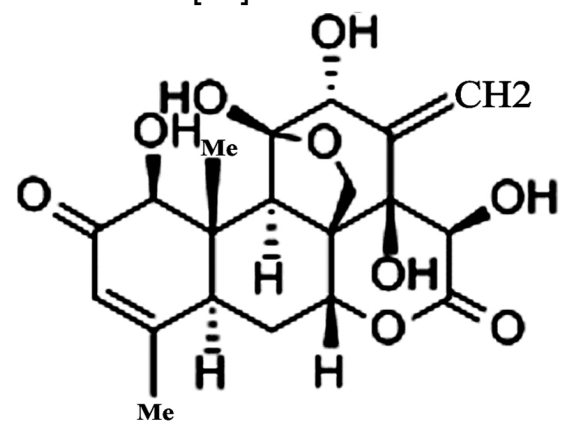

Figure 1: Chemical structure of eurycomanone.

Increased demand for $E$. longifolia as a result of its aphrodisiac properties, the availability of more than 200 products [6] and eurycomanone's toxicity require quantification of eurycomanone. Therefore, this study sought to develop and validate a RP-HPLC method for the determination of eurycomanone in E. Iongifolia.

\section{EXPERIMENTAL}

\section{Plant material}

E. longifolia root was obtained from specialized suppliers of herbal products in Malaysia (Herbagus Trading, Kepala Batas, Pulau Pinang; Delima Jelita Herbs, Alor Setar, Kedah; Mardi Telong, Bachok, Kelantan). The raw plant material was dried at $40^{\circ} \mathrm{C}$ and ground into fine powder. Six marketed commercial products (all registered in Malaysia by the National Pharmaceutical Control Bureau) containing $E$. longifolia root were randomly purchased during 2011 from different pharmacies in Pulau Pinang, Malaysia.

\section{Chemicals and reagents}

Eurycomanone reference compound was purchased from ChromaDex, (Irvine, California). Solvents of analytical or of HPLC grade were purchased from Merck Sdn. Bhd. (46150 Petaling Jaya, Selangor, Malaysia). Deionized water for HPLC analysis was prepared using a Thermo Scientific Barnstead Gen Pure water purifier system.

\section{Optimization of extraction procedure}

Extraction was optimized by varying the ratio of water to the root powder and extraction time. Water extracts were prepared by reflux for three (3) cycles where fresh water was added in each cycle. The extracts were combined, concentrated by rotavapor at $60^{\circ} \mathrm{C}$ and dried in a freeze-dryer (ScanVac, LaboGene). Eurycomanone peak area was analyzed by HPLC (see next sections) as the parameter for selection of the best extraction conditions.

The ethanol extract was prepared from raw material obtained from Pahang, Malaysia by Soxhlet extractor for $24 \mathrm{~h}$. The solvent was evaporated at $50{ }^{\circ} \mathrm{C}$ using rotavapor and further dried by freeze-drying to give a percent yield of $2.6 \%$. Ethanolic extract $(1 \mathrm{~g})$ was fractionated with chloroform $(50 \mathrm{ml})$ for $10 \mathrm{~min}$ using magnetic stirrer to give $200 \mathrm{mg}$. Both ethanolic extract and its chloroform fraction were used to confirm suitability of the proposed method for analysis of extracts prepared in organic solvents besides analysis of aqueous extracts.

\section{Instrumentation and chromatographic conditions}

RP-HPLC was performed using a Dionex Ultimate 3000 system equipped with degasser, quaternary pump, auto sampler, column oven and ultraviolet (UV) detector. Separation was done using Phenomenex, Luna C18 column (150 $\mathrm{mm} \times 4.6 \mathrm{~mm}, 5 \mu \mathrm{m}$ ). Column temperature was maintained at $40^{\circ} \mathrm{C}$, injection volume was $20 \mu \mathrm{l}$, and a gradient mobile phase was used which comprised of acetonitrile (A), $0.1 \%$ formic acid in water (B) (Table 1). Flow rate was maintained at $1 \mathrm{ml} / \mathrm{min}$ and UV detector was operated at a wavelength $254 \mathrm{~nm}$. Data acquisition was performed by Chromeleon software version 6.8.

\section{Preparation of standard}

Stock solution of eurycomanone standard was prepared at $0.1 \mathrm{mg} / \mathrm{ml}$ in HPLC-grade methanol, filtered through $0.45-\mu \mathrm{m}$ syringe filter and further 
diluted in the same solvent to obtain $50,25,12.5$, $6.25,3.125,1.5625,0.8,0.4,0.2,0.1 \mu \mathrm{g} / \mathrm{ml}$.

Table 1: HPLC gradient mobile phase operating parameters

\begin{tabular}{lccc}
\hline Time (min) & $\begin{array}{c}\text { Flow rate } \\
\text { (ml/min) }\end{array}$ & \%A & \% B \\
\hline 0 & 1.0 & 10 & 90 \\
13 & 1.0 & 25 & 75 \\
15 & 1.0 & 10 & 90 \\
20 & 1.0 & 10 & 90 \\
\hline A = acetonitrile and B $=0.1 \%$ formic acid
\end{tabular}

\section{Preparation of samples}

Two hundred fifty milligram of dried extracts was dissolved in $10 \mathrm{ml}$ HPLC-grade methanol, sonicated for $15 \mathrm{~min}$, filtered through $0.45-\mu \mathrm{m}$ syringe filter and further diluted to $5 \mathrm{mg} / \mathrm{ml}$. For commercial products, the content of 20 capsules was mixed thoroughly and $250 \mathrm{mg}$ was extracted for $15 \mathrm{~min}$ by sonication in $10 \mathrm{ml}$ methanol, and filtered through $0.45-\mu \mathrm{m}$ syringe filter (the final concentration was $25 \mathrm{mg} / \mathrm{ml}$ ).

\section{Method validation}

The method was validated according to the guidelines of International Conference on Harmonization [18]. The following validation characteristics were evaluated: selectivity, linearity, precision, accuracy and the limits of detection and quantification (LOD and LOQ).

\section{Linearity}

Linearity was determined by injecting $20 \mu \mathrm{l}$ of the standard eurycomanone in a concentration range $0.1-50 \mu \mathrm{g} / \mathrm{ml}$. The calibration curve was obtained by plotting the peak area versus concentration, and linearity was determined as the regression coefficient $\left(R^{2}\right)$ of calibration graph.

\section{Selectivity}

Method's selectivity was determined by comparing retention time of eurycomanone obtained in the sample with that of reference compound, and by spiking the extract with reference compound.

\section{Precision}

Reproducibility of peak area and retention time was determined as relative standard deviation (\%RSD). The standard compound was analyzed at 5 concentrations $(3.125-50.0 \mu \mathrm{g} / \mathrm{ml})$, and the intraday, interday and intermediate precisions were calculated $(n=5)$.

\section{Accuracy}

Accuracy was determined as a percentage recovery of eurycomanone, added to the $E$. longifolia extract at $1 \mathrm{mg} / \mathrm{ml}$. The recovery was studied at $25,12.5,6.25$ and $3.125 \mu \mathrm{g} / \mathrm{ml}$ of reference compound. Peak areas of the compound in the extract $(W)$, reference compound $(Z)$ and their combinations $(X)$ were recorded. Percent recovery was calculated as in Eq 1 [19] and the results are presented as mean $\pm \operatorname{SD}(n=3)$.

$\%$ Recovery $=\{(X-W) / Z\} 100$

\section{Limits of detection (LOD) and quantification (LOQ)}

The LOD and LOQ were calculated using slope and standard deviation method [18] according to Eqs 2 and 3.

LOD $=(3.3 \times \delta) / S$

$\mathrm{LOQ}=(10 \times \delta) / \mathrm{S}$

where $\delta$ : is the standard deviation of the $Y$ intercept of the linear regression equation, and $S$ is the slope of the linear regression equations.

\section{Determination of eurycomanone concentration in E. longifolia extracts and commercial products}

Twenty microliters of $E$. longifolia extracts or commercial products were injected, and the peak area corresponding to eurycomanone was recorded. Concentration of marker compound in the samples was calculated by applying the linear regression equation of the standard calibration curve, and the content ( $w t \%, n=3$ ) was calculated as in Eq 4.

Content $(\mathrm{wt} \%)=(\mathrm{Cf} / \mathrm{Cs}) 100$

where $\mathrm{Cf}$ is the found concentration and $\mathrm{Cs}$ is concentration of the sample.

\section{Statistical analysis}

Statistical calculations were carried out using SPSS 16.0 software package. Student's t-test was applied, and differences were considered significant at $P<0.05$.

\section{RESULTS}

\section{Extraction}

Extraction was carried out at three reflux cycles each at 4, 6, or $8 \mathrm{~h}$. At the beginning, the solvent: 
root powder ratio was set at 10:1; percent eurycomanone (wt/wt) was recorded by HPLC and was found to be $0.65 \pm 0.00(4 \mathrm{~h}), 0.58 \pm$ 0.00 (6 h) and $0.48 \pm 0.00$ ( $8 \mathrm{~h})$. Consequently, extraction time was set at $4 \mathrm{~h}$ per cycle and the solvent ratio was maintained at $15: 1$ or $20: 1$; percentage of eurycomanone (wt/wt) was $0.90 \pm$ $0.01(15: 1)$ and $0.74 \pm 0.01(20: 1)$. Our results suggested the best extraction conditions at water: root powder ratio of 15: 1 and at 3 reflux cycles each for $4 \mathrm{~h}$. Therefore, E. longifolia water extracts of the root were prepared under these conditions.

\section{Maximum wavelength of absorbance}

The maximum absorbance of eurycomanone was determined by scanning the compound in the UV-Vis wavelength range $500-200 \mathrm{~nm}$ (Figure 2). The results showed maximum absorbance in the range $248-255 \mathrm{~nm}$. The wavelength in the proposed HPLC method was therefore set at $254 \mathrm{~nm}$ in order to avoid any interference due to presence of methanol.

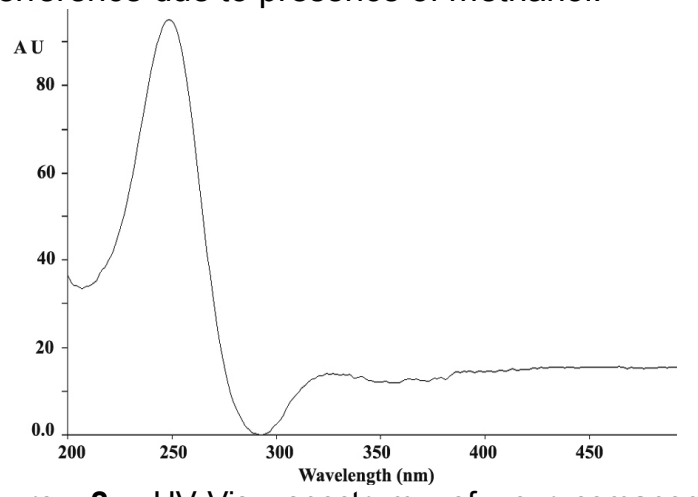

Figure 2: UV-Vis spectrum of eurycomanone reference compound, $\lambda_{\max }$ was between 248 and 255 $\mathrm{nm}$.

\section{Selectivity}

The method's selectivity was determined by comparing the retention time of eurycomanone obtained in the sample extracts with that of reference compound. Retention time of reference compound was 5.61 $\pm 0.004 \mathrm{~min}$, and the average retention time of the compound in $E$. longifolia extracts and commercial products was $5.62 \pm$ $0.02 \mathrm{~min}$. Statistical analysis by student's t-test indicated no significant difference in retention time between reference and the compound from extracts $(p=0.227)$. Additionally, spiking the extract with eurycomanone reference compound did not result in any new peaks or any shift in retention time. Altogether, these findings confirm the identity of eurycomanone and hence selectivity of the proposed method towards eurycomanone in E. longifolia extracts.

\section{Linearity}

Linearity was presented in terms of regression coefficient $\left(R^{2}\right)$ and was $>0.999$.

\section{Precision}

Precision is presented in terms of \%RSD of retention time and peak area $(n=5)$ of eurycomanone standard. The \%RSD was less than $0.14 \%$ which indicated good reproducibility of retention time. The \%RSD of peak area was calculated in the range $3.125-50 \mu \mathrm{g} / \mathrm{ml}$ and the average was less than $2.75 \%$ (Table 2 ).

\section{Accuracy}

Accuracy was determined as percent recovery of the marker compound at four concentrations. The mean percentage recovery at $3.125,6.25$, 12.5 and $25 \mu \mathrm{g} / \mathrm{ml}$ was $99.8 \pm 6.7,94.2 \pm 3.9$, $95.2 \pm 2.5$ and $97.7 \pm 2.1 \%$, respectively.

\section{LOD and LOQ}

LOD and LOQ were calculated through the slope and standard deviation of the linear regression equations (Table 3).

\section{Concentration of eurycomanone in $E$. longifolia extracts and commercial products}

Extracts and commercial products of E. longifolia were analyzed by the proposed method, and the chromatograms are displayed in Figure 3 . The chromatograms showed the presence of eurycomanone as the major compound in $E$. longifolia root extracts.

The peak corresponding to eurycomanone was integrated, and peak area recorded. Eurycomanone concentration in $E$. Iongifolia extracts was calculated by applying the linear regression equation of reference compound, and the results are presented as mean $\% \mathrm{w} / \mathrm{w} \pm \mathrm{SD}$ (Table 4 and 5).

HPLC analysis of a chloroform fraction of ethanol extract showed higher peak area of the other molecules with good resolution (Figure 4). More than 10 separated peaks can be seen in this chromatogram which may indicate our method as a good analytical tool for quality control assurance of $E$. longifolia extracts and commercial products. In this study, eurycomanone was analyzed as a possible indicator of activity and safety of TA products. 
Table 2: Precision analysis of retention time and peak area in terms of \%RSD; retention (RT) time and peak area (PA) are presented as mean \pm SD $(n=5)$

\begin{tabular}{|c|c|c|c|c|c|}
\hline \multirow[t]{2}{*}{ Precision } & \multirow{2}{*}{$\begin{array}{c}\text { Concentration } \\
(\mu \mathrm{g} / \mathrm{ml})\end{array}$} & \multicolumn{2}{|c|}{ RT (min) } & \multicolumn{2}{|c|}{ PA (mAU) } \\
\hline & & $\mathrm{AV} \pm \mathrm{SD}$ & \%RSD & $\mathrm{AV} \pm \mathrm{SD}$ & \%RSD \\
\hline \multirow[t]{5}{*}{ Intraday } & 3.125 & $5.6 \pm 0.003$ & 0.13 & $0.42 \pm 0.007$ & 2.44 \\
\hline & 6.25 & $5.6 \pm 0.003$ & 0.10 & $0.84 \pm 0.009$ & 1.78 \\
\hline & 12.5 & $5.6 \pm 0.002$ & 0.05 & $1.64 \pm 0.007$ & 0.69 \\
\hline & 25 & $5.6 \pm 0.002$ & 0.08 & $3.27 \pm 0.028$ & 1.00 \\
\hline & 50 & $5.6 \pm 0.003$ & 0.06 & $6.51 \pm 0.045$ & 1.03 \\
\hline \multirow[t]{5}{*}{ Interday } & 3.125 & $5.6 \pm 0.003$ & 0.05 & $0.42 \pm 0.012$ & 2.74 \\
\hline & 6.25 & $5.6 \pm 0.004$ & 0.07 & $0.84 \pm 0.005$ & 0.54 \\
\hline & 12.5 & $5.6 \pm 0.002$ & 0.03 & $1.65 \pm 0.005$ & 0.28 \\
\hline & 25 & $5.6 \pm 0.001$ & 0.03 & $3.28 \pm 0.021$ & 0.65 \\
\hline & 50 & $5.6 \pm 0.002$ & 0.04 & $6.48 \pm 0.043$ & 0.66 \\
\hline \multirow[t]{5}{*}{ Intermediate } & 3.125 & $5.6 \pm 0.002$ & 0.04 & $0.42 \pm 0.001$ & 0.30 \\
\hline & 6.25 & $5.6 \pm 0.004$ & 0.07 & $0.84 \pm 0.001$ & 0.07 \\
\hline & 12.5 & $5.6 \pm 0.007$ & 0.13 & $1.64 \pm 0.006$ & 0.33 \\
\hline & 25 & $5.6 \pm 0.001$ & 0.03 & $3.27 \pm 0.007$ & 0.15 \\
\hline & 50 & $5.6 \pm 0.005$ & 0.08 & $6.50 \pm 0.023$ & 0.35 \\
\hline
\end{tabular}

Table 3: Calibration data for RP-HPLC method (mean \pm SD, $n=5$ ).

\begin{tabular}{|c|c|c|c|c|c|c|}
\hline \multirow{2}{*}{$\begin{array}{l}\boldsymbol{A} \\
0.13 \pm 0.0004\end{array}$} & $c$ & \multicolumn{2}{|c|}{$\delta$} & $\begin{array}{l}\mathrm{LOD} \\
\mu \mathrm{g} / \mathrm{ml}\end{array}$ & $\begin{array}{c}\mathrm{LOQ} \\
\mathrm{\mu g} / \mathrm{ml}\end{array}$ & $R^{2}$ \\
\hline & $0.028 \pm 0.009$ & \multicolumn{2}{|c|}{$0.011 \pm 0.004$} & $0.29 \pm 0.1$ & $0.887 \pm 0.30$ & $1.0 \pm 0.00001$ \\
\hline \multicolumn{7}{|c|}{$\begin{array}{l}\text { The linear regression equation is: } y=a x+c, \delta \text { refers to the standard deviation of the } y \text {-intercept. LOD and LOQ refer to the } \\
\text { limits of detection and quantification, respectively. }\end{array}$} \\
\hline Item code & Plant part & Location & Extract & $\%$ Yield & $\%$ Euryc & lone (w/w) \\
\hline TA-R-C & Root & Pahang & Water & 6.01 & & 0.03 \\
\hline TA-R-A & Root & Perak & Water & 7.22 & & 0.04 \\
\hline TA-R-B & Root & Selangor & Water & 9.25 & & 0.01 \\
\hline TA-R-K & Root & Kedah & Water & 10.62 & & 0.01 \\
\hline TA-R-D & Root & Kelantan & Water & 4.08 & & 0.01 \\
\hline
\end{tabular}

Table 5: Concentration of eurycomanone in E. longifolia commercial products. Results are shown as mean \pm SD $(\mathrm{n}=5)$

\begin{tabular}{cccc}
\hline Brand & Items code & E. longifolia part & \% Eurycomanone (wt/wt) \\
\hline A & TA-F1 & Root & $0.11 \pm 0.00$ \\
B & TA-F2 & Root & $0.12 \pm 0.00$ \\
C & TA-F3 & Root & $0.07 \pm 0.00$ \\
D & TA-F4 & Root & $0.12 \pm 0.00$ \\
E & TA-F5 & Root & $0.11 \pm 0.00$ \\
F & TA-F6 & Root & $0.16 \pm 0.00$ \\
\hline
\end{tabular}



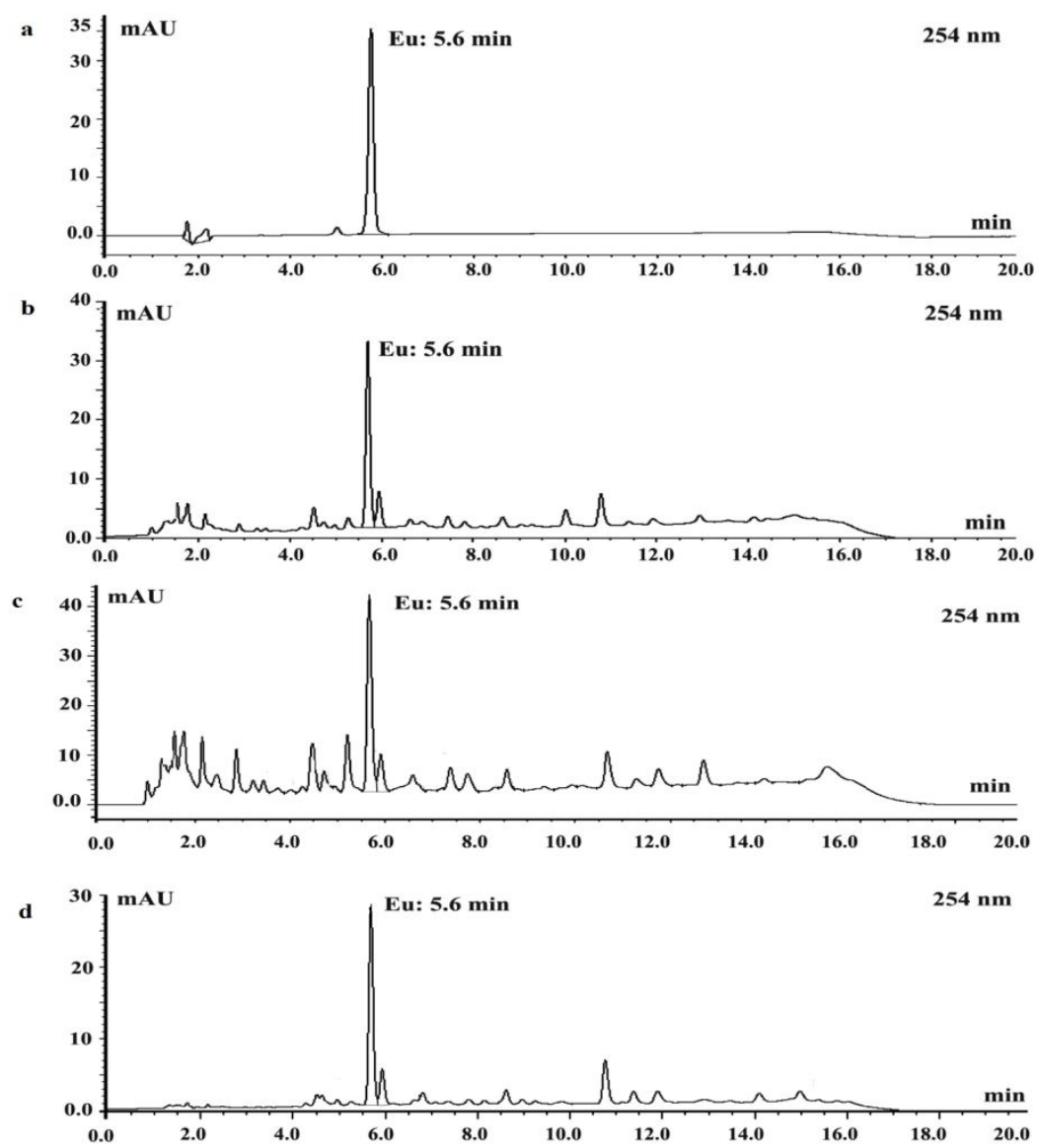

Figure 3: HPLC chromatograms of E. longifolia extracts and commercial products at $254 \mathrm{~nm}$. Note: a = eurycomanone standard, $(b)=$ root water extract, $c=E$. longifolia commercial product TA-F6, and $d=$ ethanol root extract

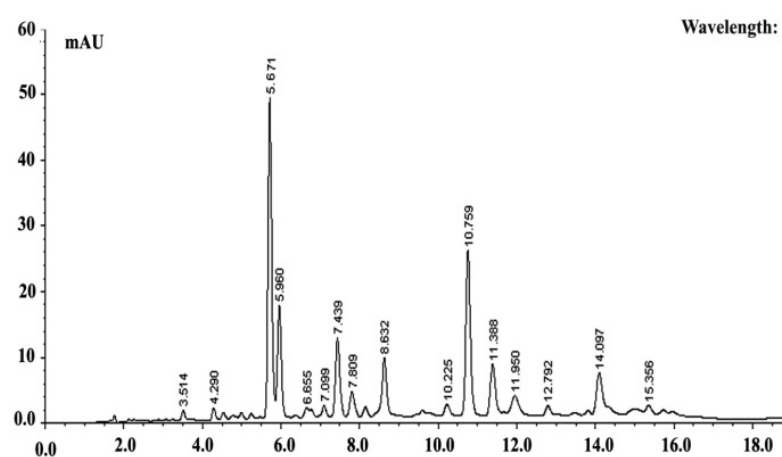

Figure 4: HPLC chromatogram of a chloroform subextract prepared from ethanol root extract of $E$. longifolia.

\section{DISCUSSION}

Eurycomanone was selected as reference compound because it has been reported as one of the major quassinoids in E. longifolia, and concentration of this compound largely contributes to biological activities of the plant $[12,20]$. Optimization of extraction procedure showed instability of eurycomanone at reflux temperature for extended period of time; this can be obviously seen in the lower percentage of eurycomanone obtained when extraction was carried out at $>4 \mathrm{~h}$ per cycle compared to extraction at $4 \mathrm{~h}$. In the ethanol extract, the percentage of eurycomanone was above the upper allowed limit (4.6\%) set by Department of Malaysian Standards $(0.8-1.5 \%)$. On the other hand, concentration in aqueous extract from the same raw material $(1.05 \%)$ falls within the allowed concentration range. The yield of the aqueous extract was higher (7.2\%) compared to $2.6 \%$ of ethanol extract. Besides, the aqueous extract was obtained in powder form whereas the ethanol extract was obtained as sticky wax which made commercial processing of the aqueous extract easier and more feasible than ethanol extract. Altogether, these findings support the use of water for extraction of $E$. longifolia root particularly for aphrodisiac effect. The use of acetonitrile at $10 \%$ and $0.1 \%$ formic acid at 90 $\%$ resulted in short elution time $(<20 \mathrm{~min})$, and eurycomanone retention time was $5.6 \mathrm{~min}$ while maintaining high resolution of several compounds in the extracts. The LOD and LOQ values indicated high sensitivity of the method; these values were comparable to those reported 
in previous methods for quantification of $E$. longifolia compounds [14]. This method can be applied in quantification of eurycomanone in aqueous extracts of the root and those prepared in organic solvents.

Good separation of the eurycomanone and other compounds was achieved in six available commercial products of E. longifolia root, which indicated that our method can also be used in quality control of Tongkat Ali commercial products. Analysis of chloroform sub-extract obtained from ethanolic extract showed the presence of more than ten isolated peaks. Consequently, and providing the availability of reference compounds, it can be concluded that our method can be used for quantification of these compounds in $E$. longifolia extracts. Overall, we report an alternative RP-HPLC method for quantification of eurycomanone in $E$. longifolia extracts and commercial products.

\section{CONCLUSION}

The developed method is rapid, selective, precise, accurate and highly sensitive. The method also demonstrates several advantages, including lower elution time while maintaining high resolution of the main compounds in the extracts, leading to lower analysis cost. The proposed method is an important contribution to the research on E. longifolia, and may be useful as an analytical tool for routine quality control assurance of $E$. longifolia in the pharmaceutical industry.

\section{ACKNOWLEDGMENT}

This research was supported by Research University Grant, Universiti Sains Malaysia (USM) (1001/PFARMASI/8120232) and partially by NKEA Monograph (401/PFARMASI/510063). The authors wish to thank Mr Thiyagu from Mardi Telong (Bachok, Kelantan) for providing the raw material used from Pahang.

\section{COMPETING INTERESTS}

The authors declare that no competing financial interests exist.

\section{REFERENCES}

1. Ang HH, Sim MK. Eurycoma longifolia increases sexual motivation in sexually naïve male rats. Arch Pharm Res. 1998; 21(6): 779-781.

2. Chan KL, Choo CY, Abdullah NR, Ismail Z. Antiplasmodial studies of Eurycoma longifolia Jack using the lactate dehydrogenase assay of
Plasmodium falciparum. J Ethnopharmacol. 2004; 92(2): 223-227.

3. Jiwajinda S, Santisopasri V, Murakami A, Kawanaka M, Kawanaka H, Gasquet M, Eilas

$R$, Balansard $G$, Ohigashi $H$. In vitro anti-tumor promoting and anti-parasitic activities of the quassinoids from Eurycoma longifolia, a medicinal plant in Southeast Asia. J Ethnopharmacol. 2002; 82(1): 55-58.

4. Kuo PC, Damu AG, Lee KH, Wu TS. Cytotoxic and antimalarial constituents from the roots of Eurycoma longifolia. Bioorg Med Chem. 2004; 12(3): 537-544.

5. Tada $H$, Yasuda $F$, Otani $K$, Doteuchi $M$, Ishihara $Y$, Shiro M. New antiulcer quassinoids from Eurycoma longifolia. Eur J Med Chem. 1991; 26(3): 345-349.

6. Bhat $R$, Karim $A A$. Tongkat Ali (Eurycoma longifolia Jack): $A$ review on its ethnobotany and pharmacological importance. Fitoterapia. 2010; 81(7): 669-679.

7. Ang $\mathrm{HH}$. An insight into Malaysian herbal medicines. Trend Pharmacol Sci. 2004; 25: 297-298.

8. Darise $M$, Kohda $H$, Mizutani $K$, Tanaka $O$. Eurycomanone and eurycomanol, quassinoids from the roots of Eurycoma longifolia. Phytochemistry. 1982; 21(8): 2091-2093.

9. Chan KL, Lee S, Sam TW, Han BH. A quassinoid glycoside from the roots of Eurycoma longifolia. Phytochemistry. 1989; 28(10): 2857-2859.

10. Chan KL, Lee SP, Sam TW, Tan SC, Noguchi $H$, Sankawa U. 13[beta], 18- dihydroeurycomanol, a quassinoid from Eurycoma longifolia. Phytochemistry. 1991; 30: 3138-3141.

11. Chan KL, O'neill MJ, Phillipson JD, Warhurst DC. Plants as sources of antimalarial drugs. Eurycoma longifolia. Planta Med. 1986; 52(2 Pt 3): 105-107.

12. Zakaria $Y$, Rahmat $A$, Pihie AHL, Abdullah NR, Houghton PJ. Eurycomanone induce apoptosis in HepG2 cells via up-regulation of p53. Cancer Cell Int. 2009; 9(16): 21

13. Phytopharmaceutical aspect of freeze dried water extract from Tongkat ali roots - Specification. Malaysia, 2011.

14. Low BS, $\mathrm{Ng} B H$, Choy WP, Yuen $K H$, Chan $K L$. Bioavailability and pharmacokinetic studies of eurycomanone from Eurycoma longifolia. Planta Med. 2005; 71(9): 803-807.

15. Choo CY, Chan KL. High performance liquid chromatography analysis of canthinone alkaloids from Eurycoma longifolia. Planta Med. 2002; 68(4): 382-384.

16. Tan S, Yuen KH, Chan KL. HPLC analysis of plasma 9methoxycanthin-6-one from Eurycoma longifolia and its application in a bioavailability/ pharmacokinetic study. Planta Med. 2002; 68(4): 355-358.

17. Chan KL, Choo CY, Morita H, Itokawa H. High performance liquid chromatography in phytochemical analysis of Eurycoma longifolia. Planta Med. 1998; 64: 741-745.

18. $\mathrm{ICH}$, Guidance for Industry, Q2B: Validation of Analytical Procedures: Methodology. International Conference on Harmonisation, USA, 1997; 2746327467.

19. Aisha A, Abu-Salah K, Siddiqui M, Ismail Z, Majid AA. Quantification of $\alpha-, \beta$ - and $\gamma$ mangostin in Garcinia mangostana fruit rind extracts by a reverse phase high performance liquid chromatography. J Med Plant Res. 2012; 6(29): 4526-4534.

20. Kardono LBS, Angerhofer CK, Tsauri S, Padmawinata K, Pezzuto LM, Kinghorn ADJ. Cytotoxic and antimalarial constituents of the roots of Eurycoma longifolia. J Nat Prod. 1991; 54(5): 1360-1367. 